\title{
Radiografia das políticas e do sistema de saúde no Brasil
}

Políticas e Sistema de Saúde no Brasil.

Giovanella, L.; ESCOREL, S.; LOBATO, L. V. C.; NORONHA, J. C.; CARVALHO, A. I. $2^{\circ}$ edição revisada e ampliada.

Rio de Janeiro: Editora Fiocruz, 2012. 1.100p.

| ${ }^{1}$ Cibeli Navarro Roldan Martin, ${ }^{2}$ Elói Martins Senhoras |

${ }^{1}$ Universidade Federal de Roraima. Boa Vista-RO, Brasil (cibellinavarro@yahoo.com.br).

2 Universidade Federal de Roraima. Boa Vista-RO, Brasil (eloisenhoras@gmail.com).

DOI: http://dx.doi.org/10.1590/S0103-73312016000200018

O livro Políticas e sistemas de saúde no Brasil, desde sua primeira edição, em 2008, tornou-se importante referência bibliográfica nas escolas brasileiras de ciências da saúde, em cursos graduação e pós-graduação, por agrupar e apresentar de forma didático-pedagógica as diversas dimensões do sistema de saúde no país, usando uma metodologia que contempla a multidisciplinaridade no campo da Saúde Coletiva.

O lançamento da segunda edição, em 2012, representa a consolidação da produção do conhecimento em Saúde Coletiva dos últimos trinta anos e reúne autores das mais diversas áreas que contribuem na construção diária do Sistema Único de Saúde (SUS) no Brasil. O maior mérito do livro é produzir competência nos alunos, ajudando a consolidar a cidadania e a construir o direito universal à saúde.

Por se tratar de uma obra coletiva, que traz uma visão sistêmica sobre as "políticas e o sistema de saúde no Brasil", com base nas pesquisas de um grupo multidisciplinar composto por 67 pesquisadores de renomadas instituições nacionais, o livro consolida-se como uma referência bibliográfica basilar para compreender os desafios estruturais e conjunturais da saúde no país. 
A obra é organizada em cinco partes, totalizando 35 capítulos. A parte I Proteção Social, Políticas e Determinantes de Saúde - busca compreender por que a política de saúde deve ser tratada como uma política social, usando conceitos de cidadania e proteção social. Segue a análise das políticas de saúde com referências nacionais e internacionais e o detalhamento da origem, da dinâmica e dos desafios do sistema de saúde brasileiro.

Metade da primeira parte discute de forma abrangente quais os determinantes sociais na saúde, na doença e na intervenção, quais as condições de saúde da população brasileira e limitações no acesso e utilização dos serviços de saúde. Há um enfoque na promoção da saúde e nas alternativas para o enfrentamento das iniquidades de acesso e o detalhamento da morbimortalidade da população brasileira, baseado nos registros oficiais do Datasus.

A parte II - Saúde como Setor de Atividade Econômica - engloba o complexo industrial da saúde, área de ciência, tecnologia e pesquisa em saúde e o trabalho e emprego em saúde. A discussão inicial refere-se à sustentabilidade estrutural do sistema de saúde e segue sobre o caráter estratégico da saúde, buscando entender o complexo industrial da saúde como importante setor produtivo e discutindo a criação de tecnologias próprias.

Embora esta seção seja a mais curta do livro, com apenas três capítulos, destacam-se as discussões tanto sobre a política pública de ciência e tecnologia em saúde no Brasil, quanto sobre o inovador mapeamento de quem são, onde estão e como são capacitados os trabalhadores de saúde no país, a fim de mostrar desafios, como a qualificação da mão de obra, a importância, quase hegemônica, da oferta de empregos em saúde por entes públicos, a incorporação de novas categorias e o predomínio do multiemprego.

A parte III - Sistema de Saúde Brasileiro: História e Configuração Atual discorre sobre a formulação e o desenvolvimento das políticas em três grandes períodos: Império e República Velha, a era Vargas e o período de desenvolvimento populista. Segue-se com a discussão sobre o período do golpe militar (19641990) e o período na Nova República, com o movimento da Reforma Sanitária e a $8^{\text {a }}$ Conferência Nacional de Saúde.

O SUS e seu modo de financiamento e alocação de recursos são apresentados nos capítulos 12 e 13, com detalhamento de seus princípios, diretrizes e espaços de participação social. A parte III encerra-se com um capítulo destinado a 
discorrer sobre o impacto dos planos e seguros de saúde privados, avaliando as perspectivas de transformação da complementaridade público-privada rumo ao direito universal à saúde.

Na parte IV - Sistema Único de Saúde: Setores de Atenção - são discutidas a atenção primária à saúde (a Estratégia de Saúde da Família e a Política Nacional de Atenção Básica), a atenção ambulatorial especializada (e o gasto da incorporação tecnológica em saúde) e as tendências para a atenção hospitalar, discutindo qual o papel atribuído aos hospitais dentro da rede integrada de serviços em saúde.

Os demais capítulos da parte IV são destinados a atenção bucal, saúde mental, assistência farmacêutica, vigilância epidemiológica e vigilância sanitária. Destaca-se que o acesso a medicamentos é considerado um marco dos sistemas de proteção social, sendo a assistência farmacêutica e a política de medicamentos um importante espaço de discussão entre o mercado capitalista produtor, a sociedade civil e os serviços de saúde.

Na parte V - Temas Relevantes em Políticas e Sistemas de Saúde - encontramse discussões aprofundadas, mas não menos didáticas, sobre bioética, reformas de sistemas de saúde, políticas sociais na América Latina, regionalização da saúde no Brasil, participação social, formação superior dos profissionais de saúde, políticas públicas para os povos indígenas, aids, cuidado continuado, política da mulher, violência e saúde e ambiente. As discussões trazidas nesta seção trazem contribuições relevantes sobre os desafios e dilemas para a construção da saúde no Brasil, de maneira a mostrar que uma multiplicidade de temas pontuais, os quais vão além das portas dos hospitais, impactam decisivamente na rotina dos profissionais da saúde e na própria eficiência das políticas e do sistema de saúde nacional.

Fruto de um audacioso projeto colaborativo entre pesquisadores de diferentes formações e de diferentes estados brasileiros, a obra caracteriza-se como um manual ou reader do campo epistemológico das políticas públicas de saúde no Brasil, que preenche uma lacuna bibliográfica existente na literatura nacional, de modo a corroborar uma ampla radiografia da saúde no país.

Com base nestas discussóes, conclui-se que o livro cumpre os objetivos a que se propõe, sendo um importante instrumento pedagógico para tornar a Saúde Coletiva possível de ser inserida em todos os níveis de ensino, inclusive, e principalmente na graduação. 
O impecável acabamento estético, aliado a um texto coerente e fluido, que reúne inúmeras autoridades em Saúde Coletiva, torna essa segunda edição de grande relevância na formação técnica e política dos profissionais de saúde no Brasil. ${ }^{1}$

\section{Nota}

${ }^{1}$ C.N.R. Martin e E.M. Senhoras participaram igualmente da concepção e redação desta resenha bibliográfica. 